\title{
An Appraisal of Farmer Variety Selection in Drought Prone Areas and Its Implication to Breeding for Drought Tolerance
}

\author{
Xavier Mhike (Corresponding author) \\ CIMMYT Southern Africa Regional Office, P. O. Box MP163, Mount Pleasant, Harare, Zimbabwe
}

Tel: 254-716-208-720 E-mail: xmhike@yahoo.co.uk

Patrick Okori

Associate Professor, Makerere University, School of Agricultural Sciences

College of Agricultural and Environmental Sciences, P.O. Box 7062 Kampala, Uganda

Girma Tesfahun Kassie

Socio Economist CIMMYT Southern Africa Regional Office

P.O. Box MP163 Mount Pleasant Harare, Zimbabwe

Cosmos Magorokosho

Maize Breeder CIMMYT Southern Africa Regional Office

P.O. Box MP163 Mount Pleasant Harare, Zimbabwe

Shamiso Chikobvu

Socio Economist Ministry of Agriculture, Ngungunyana Building

1 Borrowdale Road Harare, Zimbabwe

Received: December 4, 2011 Accepted: January 29, 2012 Online Published: April 17, 2012

doi:10.5539/jas.v4n6p27

URL: http://dx.doi.org/10.5539/jas.v4n6p27

The Research was done in Zimbabwe with Funding from Regional University Forum for Capacity Building in Agriculture (RUFORUM) and CIMMYT.

\begin{abstract}
Maize production and productivity among small scale farmers of southern Africa is limited mainly by drought and low soil fertility. This study aimed at assessing how farmers prioritize selection of varieties for planting under drought stress and how this could help improve the breeding approaches for varieties for resource constrained farmers in marginal environments. A survey was conducted in two drought prone districts of Zimbabwe. Data collection was done using a structured questionnaire, key informant interviews and focus group discussions. The study revealed that farmers have limited options for drought tolerant varieties available on the market. Contrary to breeders, farmers in drought prone areas do not consider disease resistance as an important trait. The farmer preferred traits include, high yield potential, drought tolerance, early maturity, and good performance even under poor soil conditions. Drought tolerance associated traits such as resistance to leaf rolling, tassel blast, general plant recovery to stress and stay green characteristics were identified as the most important traits but most of the varieties currently available on the market do not have these traits. The farmers were willing to make trade-offs among traits like taste or disease resistance for increased yield potential when selecting varieties to grow. Traits preferences or ranking and possible trade-offs were specific to specific areas and groups of farmers. In this study farmers still planted the traditional varieties or landraces because they are
\end{abstract}


drought tolerant, taste better and can be propagated from farm saved seed. These findings show that farmers have limited options on drought tolerant varieties on the market and that scientists need to tap into farmer knowledge, especially on possible trade offs, trait ranking and germplasm for use in developing better adapted varieties which are specific to target farmers. Policies and seed systems analysis on variety availability, distribution and marketing channels also need to be strengthened.

Keywords: Drought tolerance, Farmer knowledge, Productivity, Trait preferences, Trait-trade-offs

\section{Introduction}

Maize (Zea mays L.) has accounted for 22 to 25 percent of starchy staple consumption in Africa from 1980, representing the largest single source of calories, followed closely by cassava. The highest amounts of maize consumed are found in Southern Africa at $85 \mathrm{~kg} / \mathrm{capita} /$ year as compared to 27 in East Africa and 25 in West and Central Africa (Langyintuo et al 2008; Smale et al., 2011). In Lesotho, Malawi, South Africa, Zambia and Zimbabwe, average consumption is over $100 \mathrm{~kg} / \mathrm{capita} / \mathrm{year}$. These amounts represent more than 50 percent of total calories in Lesotho, Malawi and Zambia, 43 percent in Zimbabwe, and 31 percent in South Africa (Smale et al., 2011). Thus, for some countries in sub-Saharan Africa, maize is important enough in farm production, incomes and diets that yield gains could have impacts on producer and consumer welfare similar to those that occurred with improved rice in Southeast Asia (Larson et al., 2010.)

However maize is highly susceptible to drought, making it a high-risk crop for semi-arid areas, despite it occupying an essential place in the livelihoods and food security considerations of a vast majority of sub-Saharan Africa farmers. Many of the countries in sub-Saharan Africa are drought prone receiving on average about 300-600 $\mathrm{mm}$ of rain per year with very high variability. In such areas, severe drought occurs every 5-8 years whilst variations in length of the rainy season may be more frequent $(F A O, 2010)$. Crop growth cycles are thus subject to drought leading to severe yield losses. According to World Bank (2006) it is expected that the effects of climate change will be most severe in sub Saharan Africa.

As a result in the sub Saharan Africa region food security is the most important livelihood objective of farmers as producing sufficient food for the family is always the number one priority of farming households. Maize is a crop that easily fits into the strategic activities of farmers because diverse varieties have been bred and made available for high to low productivity potential areas. More than $80 \%$ of the farmers in southern Africa grow maize almost exclusively on a rain-fed basis yet have limited capacity to irrigate the crop especially among smallholder farmers rendering them prone to drought stress. Concomitantly, as a safety net to this vulnerability, most smallholder farmers in Zimbabwe and most of sub Saharan Africa put a big proportion of their farms under maize as a compensatory measure for low productivity at the disadvantage of other crops (Chikobvu et al., 2010).

Developing drought-tolerant varieties can boost harvests in many African countries by 10 to $34 \%$ and generate more than US $\$ 1.5$ billion in benefits for producers and consumers (La Rovere et al., 2010). Zimbabwe is divided into five ecological zones with the majority of smallholder farmers found in the drought prone ecological zones III, IV, and V that are marginal for maize production. As such, development and dissemination of drought tolerant maize varieties among resource-poor smallholder farmers is urgently needed. However, in order to enhance adoption of drought tolerant varieties, a participatory variety development is one of the options needed to capture farmer perspectives and assure ownership of new varieties (Banziger et al., 2001). As a result of wide-scale adoption of drought tolerant maize varieties, farmers are likely to be more food secure and can afford to allocate less land to maize and invest in other crops for a more balanced diet and improved soil fertility (Chikobvu et al., 2010).

Conventional maize breeding programs are mostly effective at developing varieties in fairly homogeneous farming systems but less effective when farmer reality is more complex and risk prone (Almerkinders et al., 2001). Traditional breeding approaches, have not considered the special farmer preferences especially in the semi-arid or stress environments (Banziger and Cooper, 2001). For example, in Kenya, a country where maize production occurs in marginal semi-arid zones, farmers prefer early maturing varieties ahead of increased yield potential, indicating that farmer preferences may not be congruent to conventional breeding objectives (De Groote et al., 2002). Such trait trade-offs are often overlooked in traditional breeding and may account in part for low adoption rates of some very 'good varieties'.

Smallholder farmer involvement in Participatory Plant Breeding (PPB) and Participatory Variety Selection (PVS) has been done on pearl millet in Namibia (Monyo et al., 2001) and maize using the Mother Baby Trials in the SADC region (Banziger and de Meyer, 2002). Participatory research with farmers generates the right research questions for scientists to address and provides a reality check on the scientists' conceptions of system constraints 
and the performance of various technologies (Almerkinders et al., 2001). Therefore, the aim of this study was to establish the factors that farming households consider when making decisions regarding selection of maize varieties for production in drought prone areas. The remainder of the paper is structured as follows; methodology and/ or study area description, sampling procedure, collection and data analysis; This is then followed by results; discussion and conclusion sections.

\section{Methodology}

\subsection{Description of the Survey Area}

The study was conducted in the agro-ecological regions III and IV which on average receive less than $600 \mathrm{~mm}$ of rain per annum and where most of Zimbabwe's smallholder farmers live and depend largely on rain-fed agriculture (Figure 1). The study specifically targeted smallholder farmers in drought prone areas and marginal soils where selection of varieties is very meticulous and detailed. Two drought prone districts namely Mutoko and Zimuto were selected for the study. Mutoko communal lands (Mashonaland East Province) are located in the North Eastern part of Zimbabwe. Mutoko district lies between latitude $18-19.5^{0} \mathrm{~S}$ and longitude $31-32^{\circ} \mathrm{E}$ and is $1244 \mathrm{~m}$ above sea level. Zimuto communal lands (Masvingo Province), lie between latitude $19.5^{\circ} \mathrm{S}$ and longitude $30.8^{0} \mathrm{E}$ and is $1094 \mathrm{~m}$ above sea level (Figure 1). The selected communal areas experience a unimodal rainfall pattern with the bulk of the rains coming as sporadic heavy convectional storms annually from form NovemberMarch. In Zimuto the average rainfall as at nearby Makoholi Research Station is $425 \mathrm{~mm}$, ranging from 200- 700 $\mathrm{mm}$. The area experiences a $30-50 \%$ of mid-season droughts occurring in January. It has an average daily temperature of $27^{0} \mathrm{C}$ but temperatures can go up to $\pm 35^{\circ} \mathrm{C}$ during the summer months. Most of the soils are granite derived sands with very little organic matter. Mutoko communal lands have an average rainfall of $450 \mathrm{~mm}$, daily average temperature of $29^{\circ} \mathrm{C}$ with a more than $50 \%$ chance of a mid-season drought occurring in January. The average farm size per household in both study areas is $2.7 \mathrm{ha}$ with granite derived sands dominating.

\subsection{Sampling Procedure and Data Collection}

The selection of the wards and villages was done through simple random sampling procedure. However for the focus group discussion purposive sampling was used with one key informant being selected to represent one village. Public announcement of activities through traditional structures mainly the chief, headman and kraal heads were done during the key informants identification process. After site selection, preliminary site visits with the help of the local extension staff were done prior to conducting the appraisal. Prior to data collection, a questionnaire was prepared and pretested in Chirimuhanzu District (Midlands Province), which is also a drought prone area. Data collection was done using both a formal structured questionnaire and informal means such as focus group discussions with opinion leaders and local key informants. A questionnaire was drafted to elicit individual household information in each district. Whole community data were collected with the aid of local extension officers at ward level through transect walks. Focus group discussions to get communally shared information were done using representatives from each of the 16 villages in a district. The group discussions involved problem listing of production constraints, varieties grown and identifying the preferred traits of drought tolerant cultivars. Primary data was collected through a formal household survey with triangulation being done using local key opinion leaders that included teachers, businessmen, headmen, and agriculture extension staff. A total of 202 questionnaires were administered through face-to-face interviews. In the focus group discussions individuals and group members would at times be asked to write their contribution before a group oral discussion. Additional relevant data were also collected from secondary sources which included published and unpublished literature about agriculture production in the study areas.

\subsection{Data Analysis}

The data generated were analyzed using descriptive statistics to characterize the sample households in terms of different socioeconomic and biophysical features, while mean separation using least square means of quantitative data was done using the Statistical Package for Social Scientists (SPSS) version 17. The Principal Component Analysis (PCA) was used to generate the household level wealth indices based on asset and livestock endowments.

\section{Results}

\subsection{Household and Demographic Characteristics}

The wealth indices of the 202 households interviewed ranged from -5.473 to 24.227 (Figure 2). About $52.4 \%$ of the households were poorly endowed across the study areas. Zimuto households (average wealth index of 2.723) were better endowed than those in Mutoko (average wealth index of -0.248 ). On the categorization, about $20 \%$ 
of the sampled households were well-off, $55 \%$ scored average and $25 \%$ were poor. The mean wealth index of the poor class was -3.127 ; the average class showed a mean of 0.710 whilst the well-off mean was 8.530 .

More than half $51.5 \%$ of the sampled households were female headed. The average age of household heads in both Zimuto and Mutoko was about 50 years, with a 20 to 86 year range. The level of literacy was reasonably high in the surveyed area with $53 \%$ of the household heads having attained secondary education while about $4 \%$ of household heads were illiterate. Significant differences were observed for family size $(\mathrm{P}<0.024)$ with Mutoko (6) and Zimuto (5) as average number of people per family. There was also a significant difference in the household head gender $(\mathrm{P}<0.000)$ for the two districts with Mutoko household heads being predominantly male and Zimuto's being predominantly female. The mean farming experiences for the two districts were significantly different $(\mathrm{P}<0.003)$ with Zimuto having a higher average of 18.59 years than Mutoko with an average of 13.58 years. Zimuto district had the largest number of farmers owning animal drawn carts, oxen, chickens $(\mathrm{P}<0.000)$, TV/Radio ownership $(\mathrm{P}<0.005)$ compared to Mutoko. Farm holdings under maize in the study sites ranged from 0.2 hectares to 3 hectares. Again Zimuto had significantly total cropped area $(\mathrm{P}<0.000)$ and land put to maize production (Table 1). The study also showed that drought frequency over the last 5 years was significantly higher $(\mathrm{P}<0.000)$ for Zimuto (average of 2.55) than for Mutoko (average of 1.34). Land holding in the survey areas ranged from 0.2 hectares to 5 hectares with a mean of 1.4 hectares. Figure 3 shows the distribution of land size by wealth class. The 1 to 4 hectare range dominated among the three wealth categories.

\subsection{Maize Production Constraints and Variety Selection}

Six major constraints were highlighted by the farmers as the critical factors affecting maize production and food security in the surveyed area. These included drought, timely availability of seed and fertilizers, draft power constraints, low soil fertility, lack of knowledge on the best varieties for their respective areas and the cost of inputs. Drought as a production constraint was ranked first by $40 \%$ of the total households thus highlighting it as the main factor limiting production. Inputs and animal draft power related constraints were cited as the second and third most limiting factors to increased maize production by the farmers (Figure 4).

Farmers also indicated a number of factors they consider when buying maize seed. The highest ranked factor variety's yield potential as shown by $89 \%$ of the farmers involved in the study (Figure 5). Early maturity (< 125days to maturity) and drought tolerance traits were ranked second and third attributes considered respectively. Very few farmers (8\%) cited field pest and diseases resistance as traits considered when selecting a variety. However farmers in the two districts had different views on the ranking of traits they consider of importance when selecting varieties for stress prone environments. Zimuto farmers listed yield potential, storage pests, grain size, maturity and drought tolerance as the most important traits to consider in order of importance. The Mutoko farmers considered yield potential, drought tolerance, maturity, palatability and quality of the staple 'sadza' as the traits of importance (Table 2).

\subsection{Sources of Information on the Drought Tolerant Maize Varieties}

The combined analysis for both districts showed that the ministry of agriculture extension service was the most common source of information, followed by civil society organizations or non- governmental organizations (NGOs) and fellow farmers (Figure 6). Farmer to farmer exchange of information was significantly important for Zimuto farmers $(\mathrm{P}<0.001)$ than in Mutoko. In Mutoko, information on variety performance and characteristics came predominantly through the government extension staff and seed company personnel. This was contrary to Zimuto where NGOs had significant contribution $(\mathrm{P}<0.003)$ to information dissemination (Table 3). More than $80 \%$ of the farmers interviewed had some knowledge of drought tolerant maize varieties. About $80 \%$ of the farmers cited at least one perceived drought tolerant variety which included hybrids like R201, SC513, SC403; OPVs ZM421 and ZM521 and local landraces like 'Eight Lines' and Hickory King.

Availability of seed for planting in time and knowledge of the most ideal varieties for specific areas were indicated as major concerns. Moreover group discussions highlighted the need to have new varieties with pyramided traits for drought stress tolerance. Currently farmers plant these available varieties because they have no choice and they select these 'mediocre' varieties through ranking of traits they consider most important and making trade-offs.

\subsection{Traits Needing Improvement in Current Varieties}

Drought tolerance was ranked the top by $82 \%$ of farmer traits among that needed improvement in the current varieties, (Figure 7). This was followed by improving yield potential of the varieties with need for early maturing varieties coming third. Good performance in poor soil fertility areas and storage pest resistance were the fourth and fifth ranked factors for breeding improvement. Only $1 \%$ and $2 \%$ respectively of farmers wished for an 
improvement in the cost of seed and number of cobs per plant respectively. Farmers preferred drought tolerance traits such as stay green characteristics, leaf unrolling ability or recovery from stress, non abortion at grain filling when under stress and tassels that stay alive for a long period under stress.

\subsection{Correlation Analysis of Demographic and Crop Traits}

There were significant, strong and positive correlations between age and farming experience, area planted to maize and total farm area, yield and maturity, and drought and lodging (Table 3). Weak but positive and significant correlations were observed for maize area planted and draft power, yield and area planted to maize, and drought and variety maturity period/duration. Education, age and experience were negatively correlated to each other and the same were for drought and diseases.

Grain yield and total area planted and area planted to maize had a significant positive correlation $(\mathrm{P}<0.01)$ implying that farmers who put more land to cropping also put more land to maize and have significantly higher harvests during drought. This was also supported in the group discussion where farmers with more land planted more than one variety to spread the risk of crop failure. Positive correlations were also recorded between variety maturity and maize area $\left(\mathrm{r}=0.183^{*}\right)$, drought tolerance and early maturity $\left(\mathrm{r}=0.143^{*}\right)$ and yield and maturity $(\mathrm{r}$ $\left.=0.633^{* *}\right)$. Overall in the study area, maturity of a variety was a factor farmers considered very important when selecting a maize varieties. Most of the varieties grown were very early maturing, or drought escapees which would utilize the short growing season in the areas under study.

\section{Discussion}

\subsection{Household and Demographic Characteristics}

In Zimbabwe the traditional land tenure system still exists in communal areas, where land is owned by a clan or family or related individuals. These have user rights that may be transferred through inheritance or by the chief to another beneficiary. Under this land tenure system, wealth is measured by ownership of assets such as cattle, goats, sheep, poultry and farm implements and machinery for tilling and traction purposes. The two study districts had more goats than cattle per household because goats are generally better adapted to drier conditions than cattle. The goats in these communities are a source of food (milk and meat). However, cattle are a sign of wealth in rural Zimbabwe and are the dominant source of draught power in most households. They also provide milk, meat and manure. Television sets or radio ownership is considered very important in the rural set-up apart from being a source of entertainment, because agricultural training programs and talk-shows are aired and hence radios are also used as sources of agriculture information in Zimbabwe. Family size and age of members is critical in the rural households in Zimbabwe as it determines the amount of labour available per household as farm labour is mostly provided for by the family members.

The house wealth and demographic- approach, was also adopted in this study because findings by CIMMYT (1993) showed that resource endowments, size of family labour, livestock ownership and access to information through extension services were critical in helping farmers in variety adoption. In other studies, Almekinders et al. (2001) similarly showed that 'a farmer's decision in adopting or rejecting a new technology is influenced by a combination of factors related to farmer's objectives and constraints such as: farmer's socio-economic circumstances (age, formal education), and farmer's resource endowments (e.g. size of family labour, farm size and livestock ownership).

\subsection{Maize Production Constraints and Variety Selection}

In the districts under study, maize is the staple crop and is therefore both economically and politically important. To support maize as an economic crop a comparison of the wealth classes on the land allocated to maize showed that the average group dominated in the two categories of area under maize. The poor group had more people (21\%) with maize area under 1 hectare as compared to more than 1 hectare (Figure. 4). This showed that maize played a very important part in the livelihoods of smallholder farmers in stress prone areas. A decline in maize production due to drought and economic factors has seen the country's food basket price increase as seen in the 2008/9 season decline in maize production to below the ten year (2000- 2010) average of $0.87 \mathrm{t} / \mathrm{ha}$ (FAO 2010). The uncertainty of drought occurrence in the area of study and Zimbabwe in general results in farmers putting maize under bigger areas as a compensatory measure, thus disadvantaging other crops. This is also evident from the strong, positive and significant correlation between total land area and area planted to maize (Table 3). This finding is similar to Makanda et al. (2009) findings that maize takes more than half of the land area grown to crops in the smallholder sub-sector since it is considered a food security crop. However, in the large acreage put to the maize in the area of study farmers at times intercropped maize with legumes such as beans or cowpeas or other vegetables crops like pumpkins. 
Foliar diseases are not a factor of economic importance in the smallholder agriculture sub-sector because of the low rainfall hence reduced or no disease pressure. In the group discussions the farmers highlighted other factors they considered when assessing a variety for stress tolerance which includes drought stress traits such as; stay green characteristics, leaf unrolling ability or recovery from stress, non abortion at grain filling when under stress and tassels and silks that stay alive for a long period under stress. The recovery ability was emphasized with farmers suggesting a maize variety that could have 'sorghum drought stress recovery traits'. In other studies conducted in eastern districts of Save Valley and Mutare West Zimbabwe, similar findings were reported in which farmer requested for 'sorghum maize' and ultra early (less than 90 days to mature varieties) to avoid late season drought stress (Derera et al., 2006).

Storage pest resistance was highlighted as a very important factor to consider in Zimuto due to a previous incident where farmers grew a variety that was high yielding but was completely destroyed by weevils under storage in granaries. Susceptibility to the maize weevil, Sitopilus zeae maydis, accounted for many farmers in the area abandoning the variety despite it having a good yield. In southern Africa, farmers similarly preferred varieties with hard endosperm which is considered to confer resistance to storage pests and high maize flour production when pounding (Banziger and de Meyer, 2002). Farmers expressed willingness to make trait trade-offs for some major traits with lodging and disease resistance being considered less critical for a good yielding variety for example. Similar results have been reported on farmers' preferences on traits in eastern Kenya (Groote et al., 2002).

In general one can see that despite the two districts being drought prone ranking of production constraints were different. This implies that farmers perceive issues differently depending on their environment and hence require specific solution i.e. breeding or variety development should also be for specific environments rather than broad based.

\subsection{Sources of Information on the Drought Tolerant Maize Varieties}

Access to information through extension services from the ministry of agriculture personnel was the major source of variety information with $90 \%$ of the respondents mentioning extension staff as vital sources of information on varieties and general agriculture (Figure 8). This is the general trend in most of sub Saharan Africa where the main source of information for maize production technologies is the extension service (Zegeye et al., 2001). However information exchange among farmers also referred to as farmer to farmer knowledge transfer, is a common mechanism for sharing communally owned wisdom and any approval or otherwise of technology introduced in the area. The Zimuto case where the entire farming community abandoned a good yielding hybrid strengthens this point.

Having identified drought as the main maize production constraint, the farmers were asked to identify causes of drought and they highlighted three causes in their order of importance namely climate change, indiscriminate cutting down of trees and failure to hold traditional ceremonies. They were also asked to relate drought experience and its effects to which they associated drought with hunger, migration to urban area, selling of vegetables, survival on wild fruits, selling of livestock and failure of children to attend school. This is similar to responses reported by Mutasa et al. (2010) from a survey done in Buhera district which in the eastern part of the country. Farmers interviewed showed that they were employing more reactive than pro active coping mechanisms in their response to drought.

Inspite of the information exchange among farmers lack of knowledge on the true/ real drought tolerant was very apparent. This is because landraces such as 'Eight Lines' and Hickory King identified as drought tolerant by most farmers are late maturing and do not fully fit in the short rainy seasons of the marginal areas under study. This finding is supported by Langyintuo et al 2008 who concluded that the one of the major bottlenecks in the seed industry of Eastern and Southern Africa was lack of awareness of the availability and value of existing improved varieties.

\subsection{Reasons for Not Growing Drought Tolerant Maize Varieties}

Eighteen percent (18\%) of the respondents stated that they would continue growing the same seed varieties that they were currently growing (Figure 8) despite their poor yields due to lack of other options. Sticking to the old varieties inspite of their weaknesses is in line with the threat rigidity hypothesis (Straw et al., 1981), where farmers even under stress would stick to old solutions to their problems. In the group discussions a number of farmers highlighted the use of landraces such as 'Hickory King', 'Mukadzi Usaende' and 'Eight Line' for sadza palatability and farm saved seed. In Mutoko, farmers highlighted the growing of hybrid seed maize despite poor drought tolerance for commercial reasons where in a good season they would sell the grain to the national grain 
marketing board (GMB) while growing small plots of the landraces such as 'eight line' for home consumption because of its good taste or palatability.

This implies that there is need to improve the current varieties through introduction of stress tolerant traits by conventional or biotechnological methods. Backcross methods or gene insertions through marker assisted breeding could be pursued to improve drought tolerance of the hybrids or varieties currently on the market. There is also need for breeders to tap into the farmer germplasm for developing new varieties or improving the old landraces through participatory plant breeding and variety selection.

\subsection{Correlation Analysis of Demographic Characteristics and Crop Traits}

Significant and positive correlation $\left(\mathrm{r}=0.648^{* *}\right)$ between age and experience shows that the older farmers had more experience than the younger ones in maize production and general agricultural practice. Generally, experience and education levels are expected to influence knowledge and the farming enterprises undertaken in rural households. This is also supported by findings where variety use or adoption is influenced by the farmer's socio-economic circumstances such as age and formal education (Doss 2006; Chikobvu et al., 2010).

Draught power, age and experience are also significant $(\mathrm{P}<0.05)$ and positively correlated. This is because farmers accumulate wealth over years hence they can afford to have animals for draught power. This statistic implies that the older the household head, the better the experience and the more the chances of him or her having, draught power for timely operation. Draught power (traction) had a significant $(\mathrm{P}<0.01)$ and positive correlation with total area cropped and area under maize. Total area planted and area planted to maize have a significant and positive correlation $\left(\mathrm{r}=0.879^{* *}\right)$. Accordingly, farmers with draft power capacity planted bigger areas ploughed and planted to maize the strategic crop. The experienced farmers also had more area planted to maize $\left(\mathrm{r}=0.194^{* *}\right)$ and were more knowledgeable about drought related traits such as maturity $\left(\mathrm{r}=0.263^{* *}\right)$ and yield $\left(\mathrm{r}=0.286^{* *}\right)$. Similar findings in Ethiopia show that a farmer's resource endowments such as farm size and livestock ownership help influenced the varieties farmers grew (Zegeye et al., 2001).

Farmer preference for early maturity is consistent with previous findings, that farmers preferred these varieties because they escaped late season drought securing the harvest against crop losses (Banziger and de Meyer, 2002). In other semi arid zones of Zimbabwe, such as Chipinge and Chimanimani farmers grew short season cultivars such as SC403 and PAN413 (Derera et al. 2006). However the Mutoko farmers were unique in that they preferred early maturing open pollinated varieties (OPVs) such as ZM421 and ZM521 to hybrids.

Preference of OPVs in Mutoko can be explained by the fact that the area is drier than Zimuto and under such circumstances, OPVs are more resilient hence the demand for ZM series of synthetics. This preference of OPVs also imply that there is need for production and marketing of OPVs at community level with activities being coordinated by civil society organizations and public research breeders since most private companies do not find OPV production and marketing profitable. The group discussions also revealed that some farmers in Mutoko in the 2008/09 season were forced to grow recycled (F2) hybrid seed due to severe seed shortages. This shows the need to breed for synthetics and also trains farmers in growing OPV seed maize for use when certified seed is not readily available since this will give better yields than recycled hybrid seed.

\subsection{Traits Needing Improvement in Current Varieties and Possible Trade Offs}

The three traits of drought tolerance, good yield potential and early maturity are a priority for any variety to be considered ideal in the survey area, hence the need for more breeding effort on the three traits. The farmers' emphasis on drought tolerance improvement shows that drought tolerant varieties are currently either not satisfactory or non-existent. Early maturity is preferred by most farmers because of the need for drought escape due to the short season nature of the rains or the need to give the farmer food in the hunger season i.e. period prior to the main season harvest. Disease and pests resistance traits while ideal for full season varieties or in good seasons with increased rain and disease pressure, are not a priority for the farmers of Mutoko or Zimuto. Farmers also emphasized the need for improving the current varieties on better performance in poor soils as shown in Figure 7.

In the group discussion farmers made some key insights into variety characterization. They considered three factors namely trait degree of importance (rank), range of acceptability of a trait and trait trade-off they were willing to make when selecting desirable variety. However, most farmers interviewed used reactive strategies when confronted with problems of drought and seed shortage such as selling of livestock or sowing less area where seed shortages occurred. Proactive strategies such as conservation agriculture practices like winter ploughing, fallowing, and stable-mulching were however highlighted in some instances. Orientation for coping during drought includes praying for rain, traditional ceremonies and social support. However, innovative strategies that 
may be more effective when dealing with drought such as early or dry planting and planting drought tolerant landraces also need to be encouraged.

\section{Conclusions}

Farmers in both districts listed grain yield potential, early maturity and drought tolerance as the main traits to consider when selecting a variety to grow in drought stress prone areas. Other traits considered included variety performance under poor soil fertility conditions especially low $\mathrm{N}$, storage pests resistance and variety recovery ability from stress.

Current varieties on the market are not meeting the needs of the majority of the farmers in the stress prone smallholder sectors of Mutoko and Zimuto. The two areas are in the same agro ecological zone but the farmers had different views and preference in terms of traits to consider when selecting a variety. Farmers' preferences or choices on varieties and their traits varied with area and were shaped by their experiences and the circumstances in which they operated. This therefore calls for participatory ecosystem breeding in the target areas with farmer involvement in early stages of evaluation. Breeding and evaluation for drought stress tolerance needs to be done in the target areas where the varieties are to be deployed upon release. Landraces need be improved over time through participatory breeding and variety selection and this should be coordinated by the public sector breeding programs. More targeted training on variety characteristics, drought tolerant varieties and conservation techniques also needs to be done through joint private and public extension services. Since more NGOs supporting agriculture, there is need for closer cooperation and exchange of technical information with the NGOs, government and seed companies in order to give farmers better information and technical skills to cope with the ever increasing drought conditions especially under the threat of climate change.

\section{References}

Almekinders, C. J. M., \& Elings, A. (2001). Collaboration of farmers and breeders: Participatory crop improvement in perspective. Euphytica, 122, 425-438. http://dx.doi.org/10.1023/A:1017968717875

Banziger, M., \& de Meyer, J. (2002). Collaborative maize variety development for stress prone environments in Southern Africa. In: Farmers, Scientists and Plant Breedding. Cleveland, D.A and D Soleri (Eds.) (pp. 269-296). CAB International. http://dx.doi.org/10.1079/9780851995854.0269

Banziger, M., \& Cooper, M. (2001). Breeding for low input conditions and consequences for participatory breeding: Examples from maize and wheat. Euphytica, 122, 503 -519.

Chikobvu, S., Chiputwa, B., Langyintuo, A., La Rovere, R. \& Mwangi., W. (2010). Characterization of maize producing households in Masvingo and Bikita districts in Zimbabwe. Country Report - Zimbabwe. Nairobi: CIMMYT.

CIMMYT Highlights. (1993). The adoption of Agricultural Technologies. A Guide to Survey Design. Mexico, D. F.: CIMMYT.

De Groote, H., Siambi, M., Friesen, D., \& Diallo, A. (2002). Identifying farmers' preferences for new maize varieties in Eastern Africa. CIMMYT, Nairobi, Kenya.

Derera, J, P. Tongoona, A. Langyituo, Laing, M. D., \& Vivek, B. (2006). Farmer perceptions on maize cultivars in the marginal eastern belt of Zimbabwe and their implications for breeding. African crop Science Journal, 14(1), $1-15$.

Doss CR. (2006). The Effects of Intrahousehold Property Ownership on Expenditure Patterns In Ghana. Journal of African Economies 15 (1) 149-180

FAOSTAT. (2010). Agriculture Production. [Online] Available: http://www. faostat.fao.org/site/339/default.aspx ( July 3, 2011).

La Rovere, R, Kostandini, G, Abdoulaye, T, Dixon, J, Mwangi, W, Guo, Z, \& Banziger, M. (2010). Potential Impact of Investments. In Drought Tolerant Maize In Africa. CIMMYT, Addis Ababa, Ethiopia.

Makanda, I, Tongoona, P., \& Derera, J. (2009). Appraisal of factors impacting on crop productivity in semi arid environments in Zimbabwe and their implication on crop improvement goals and policy interventions. African Crop Science Proceedings, 9, 705 -718.

Langyintuo, A.S., Mwangi, W., Diallo, A. O., MacRobert, J., Dixon, J., \& Banziger, M. (2008). An Analysis of the Bottlenecks Affecting the Production and Deployment of Maize Seed in Eastern and Southern Africa. Harare, Zimbabwe: CIMMYT. 
Larson, Donald F., Keijiro Otsuka, Kei Kajisa, Jonna Estudillo, \& Aliou Diagne. (2010). Fostering a Green Revolution in Rice: Can Africa Replicate Asia's Experience? In Pandey,Sushil, Byerlee, Derek, Dawe, David, Dobermann, Achim, Mohanty, Samarendu, Rozelle, Scott and Hardy, Bill (eds.), Rice in the Global Economy: Strategic Research and Policy Issues for Food Security. Los Baños, Philippines: International Rice Research Institute.

Monyo, E. S, Ipinge, S.A, Heinrich, G. M., \& Chinhema, E. (2001). Participatory Breeding: Does it make a difference? Lessons from Namibian Pearl Millet Farmers. In: Assessing the impact of participatory research and gender analysis. Lilja N., J.A Ashby and L Sperling (Eds.) (pp. 198-207).

Mutasa, M. (2010). Zimbabwe's Drought Conundrum: Vulnerability and Coping. In Buhera and Chikomba Districts. MSc Degree in Development Studies Thesis Norwegian University of Life Science. Oslo. Norway.

Smale M., Byerlee D., \& Jayne T. (2011) Maize Revolution in sub Saharan Africa. World Bank Policy Research Working Paper No.5659

Sperling, L, Ashby, J. A., Smith, M. E., Weltzien, E., \& McGuire, S. (2001). A framework for analyzing participatory plant breeding approaches and results. In Montpellier, H. Hocde, J Lanc and G Trouche (Eds)., Selection participative (pp. 106-119). http://dx.doi.org/10.1023/A: 1017505323730

Staw B, Sandelands L., \& Dutton, J. (1981). The Threat Rigidity Hypothesis at a work place. Academy of Management, 21, 502. http://dx.doi.org/10.2307/2392337

World Bank. (2006). Investing in Drought Preparedness. The Water and Food Team. Available at: http://www.worldbank.org

Zegeye, T., Tadesse, B., \& Tesfaye, S. (2001). Determinants of adoption of improved maize technologies in major maize growing regions of Ethiopia. Proceedings of the Second National Maize workshop of Ethiopia, 125-136. 
Table 1. Demographics and Wealth Ranking

\begin{tabular}{|c|c|c|c|c|c|}
\hline \multicolumn{3}{|l|}{ 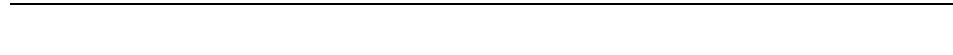 } & \multirow{3}{*}{$\begin{array}{c}\text { Masvingo } \\
\text { Zimuto } \\
\end{array}$} & \multirow{3}{*}{$\begin{array}{c}\text { Mash East } \\
\text { Mutoko } \\
\end{array}$} & \multirow[t]{3}{*}{$P$ value } \\
\hline \multicolumn{3}{|l|}{ General Information } & & & \\
\hline & & & & & \\
\hline Number of Households Intervie & (n) & & 103 & 99 & \\
\hline Average number per household & (n) & & 4.99 & 5.72 & 0.024 \\
\hline \multirow[t]{3}{*}{ Modal age range of farmers } & & years & & & \\
\hline & Male & $15-65$ & 1.04 & 1.41 & 0.006 \\
\hline & Female & $15-65$ & 1.53 & 1.44 & 0.532 \\
\hline \multirow[t]{2}{*}{ Household Head Gender } & Male & & 38 & 60 & 0.000 \\
\hline & Female & & 65 & 39 & 0.000 \\
\hline House Head Average Age & (years) & & 48.4 & 47.6 & \\
\hline House Head Age Range & (years) & & $22-77$ & $20-86$ & \\
\hline \multicolumn{2}{|c|}{ House Head mean years in farming (years) } & & 18.59 & 13.58 & 0.003 \\
\hline \multirow[t]{4}{*}{ House Head Marital Status } & Married & & 62 & 77 & 0.050 \\
\hline & Single & & 0 & 4 & \\
\hline & Divorced & & 4 & 0 & \\
\hline & Widowed & & 37 & 18 & 0.000 \\
\hline \multirow[t]{4}{*}{ House Head Education Level } & Illiterate & & 1 & 7 & 0.020 \\
\hline & Primary & & 40 & 40 & \\
\hline & Secondary & & 58 & 49 & 0.001 \\
\hline & Tertiary & & 4 & 3 & \\
\hline \multicolumn{6}{|l|}{ Assets Owned } \\
\hline \multicolumn{2}{|l|}{ Vehicle } & & 0.06 & 0.00 & 0.088 \\
\hline \multicolumn{2}{|l|}{ Motorcycle } & & 0.01 & 0.00 & 0.328 \\
\hline \multicolumn{2}{|l|}{ Bicycle } & & 0.25 & 0.21 & 0.512 \\
\hline \multicolumn{2}{|l|}{ Animal Plough } & & 0.72 & 0.71 & 0.892 \\
\hline \multicolumn{2}{|l|}{ Animal Drawn-cart } & & 0.43 & 0.20 & 0.000 \\
\hline \multicolumn{2}{|l|}{ TV/Radio } & & 0.56 & 0.33 & 0.005 \\
\hline \multicolumn{2}{|l|}{ Water Source } & & 0.69 & 0.19 & 0.000 \\
\hline \multicolumn{2}{|l|}{ Water Tank } & & 0.06 & 0.01 & 0.062 \\
\hline \multicolumn{2}{|l|}{ Mobile/ Fixed Phone } & & 0.57 & 0.37 & 0.015 \\
\hline \multicolumn{2}{|l|}{ Oxen } & & 0.57 & 0.09 & 0.000 \\
\hline \multicolumn{2}{|l|}{ Goats } & & 2.04 & 2.75 & 0.332 \\
\hline \multicolumn{2}{|l|}{ Sheep } & & 0.00 & 0.07 & 0.063 \\
\hline \multicolumn{2}{|l|}{ Transport Animals } & & 0.35 & 0.03 & 0.185 \\
\hline \multicolumn{2}{|l|}{ Draught Animals } & & 0.88 & 0.79 & 0.595 \\
\hline Pigs & & & 0.12 & 0.30 & 0.070 \\
\hline Chicken & & & 10.16 & 6.81 & 0.000 \\
\hline Cropping Data & & & & & \\
\hline Mean Household area cropped & & & 1.80 & 1.00 & 0.000 \\
\hline Mean Household area under ma & 2009) & & 1.16 & 0.62 & 0.000 \\
\hline Mean Drought years in last 5 ye & & & 2.55 & 1.34 & 0.000 \\
\hline
\end{tabular}


Table 2. Variety Information and Selection Criteria

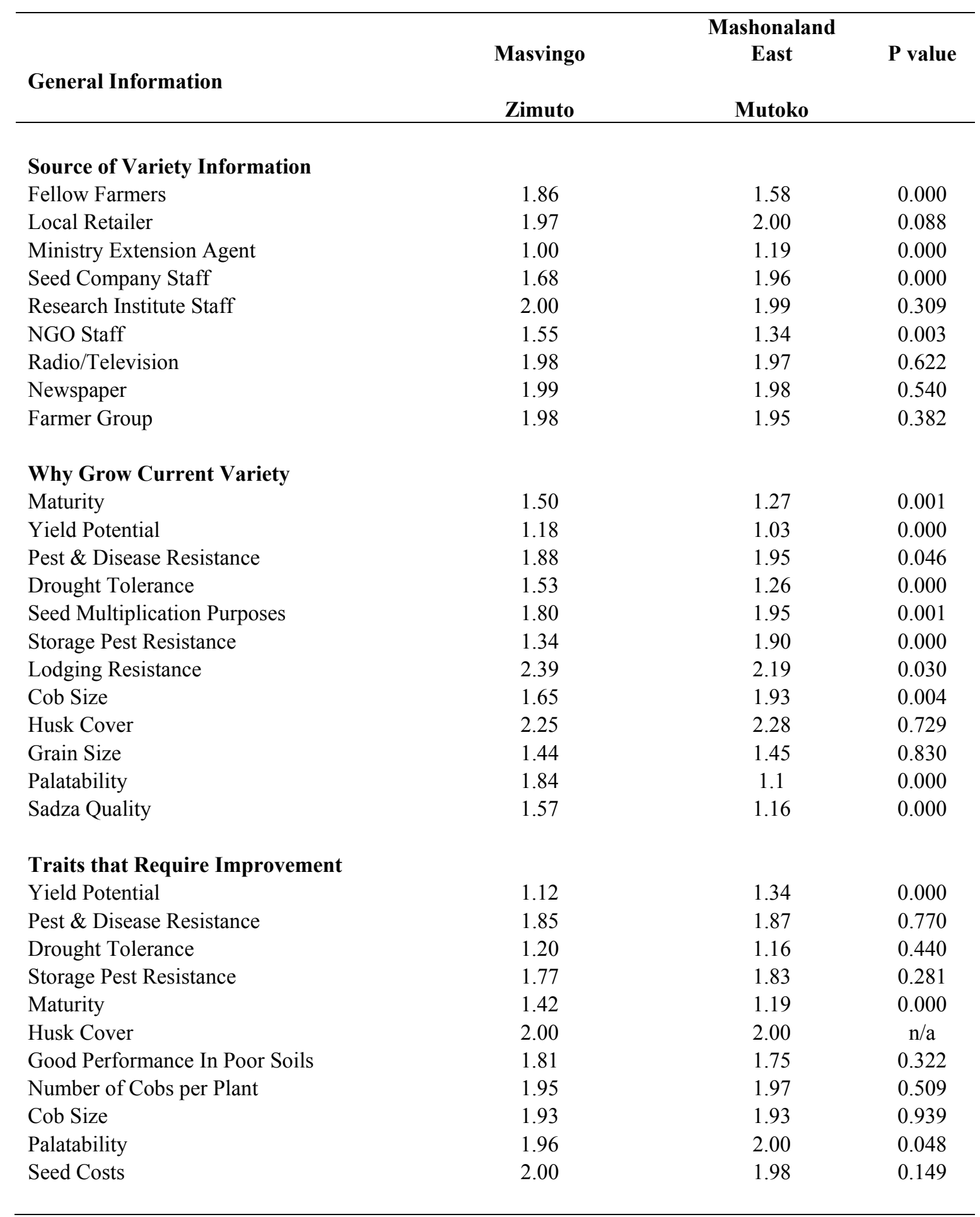


Table 3. Correlation Analysis of Demographic Characteristics and Crop Traits

\begin{tabular}{|c|c|c|c|c|c|c|c|c|c|c|c|c|c|}
\hline & Age & Gender & Exper & Education & Draft Power & Tot. area & Maize area & Dizz/pests & Maturity & Yield & Lodging & Huskcover & Drought \\
\hline Age & 1 & & & & & & & & & & & & \\
\hline Gender & 0.094 & 1 & & & & & & & & & & & \\
\hline Exp & $0.648^{* *}$ & 0.013 & 1 & & & & & & & & & & \\
\hline Education & $0.451^{* *}$ & $0.176^{*}$ & $0.231 * *$ & 1 & & & & & & & & & \\
\hline Draft & & & & & & & & & & & & & \\
\hline Power & $0.211^{* *}$ & $0.164 *$ & $0.145^{*}$ & 0.016 & 1 & & & & & & & & \\
\hline Tot. area & $0.164^{*}$ & 0.005 & $0.263^{* *}$ & 0.093 & $0.223 * *$ & 1 & & & & & & & \\
\hline Maize area & $0.129 *$ & 0.009 & $0.194^{* *}$ & 0.110 & $0.246^{* *}$ & $0.879 * *$ & 1 & & & & & & \\
\hline Dizz/pests & 0.070 & 0.101 & 0.007 & 0.031 & 0.034 & $0.335^{* *}$ & 0.116 & 1 & & & & & \\
\hline Maturity & $0.223^{* *}$ & $0.189 * *$ & $0.263^{* *}$ & 0.045 & 0.083 & $0.286^{* *}$ & $0.183 *$ & 0.081 & 1 & & & & \\
\hline Yield & $0.148^{*}$ & $0.143^{*}$ & $0.283^{* *}$ & 0.072 & 0.097 & $0.276^{* *}$ & $0.244 * *$ & 0.120 & $0.633^{* *}$ & 1 & & & \\
\hline Lodging & 0.075 & 0.052 & 0.099 & 0.049 & 0.119 & 0.043 & 0.052 & $0.133^{*}$ & $0.152^{*}$ & $0.165^{*}$ & 1 & & \\
\hline Husk cover & 0.053 & 0.045 & $0.169^{*}$ & 0.061 & 0.049 & 0.094 & 0.044 & 0.021 & $0.356^{* * *}$ & 0.096 & 0.013 & 1 & \\
\hline Drought & 0.062 & 0.127 & 0.110 & $0.157^{*}$ & 0.137 & 0.040 & 0.032 & $0.193^{* *}$ & $0.143^{*}$ & $0.137 *$ & $0.509^{*}$ & 0.017 & 1 \\
\hline
\end{tabular}




\section{Map 1: Zimbabwe Agro-Ecological Zones}

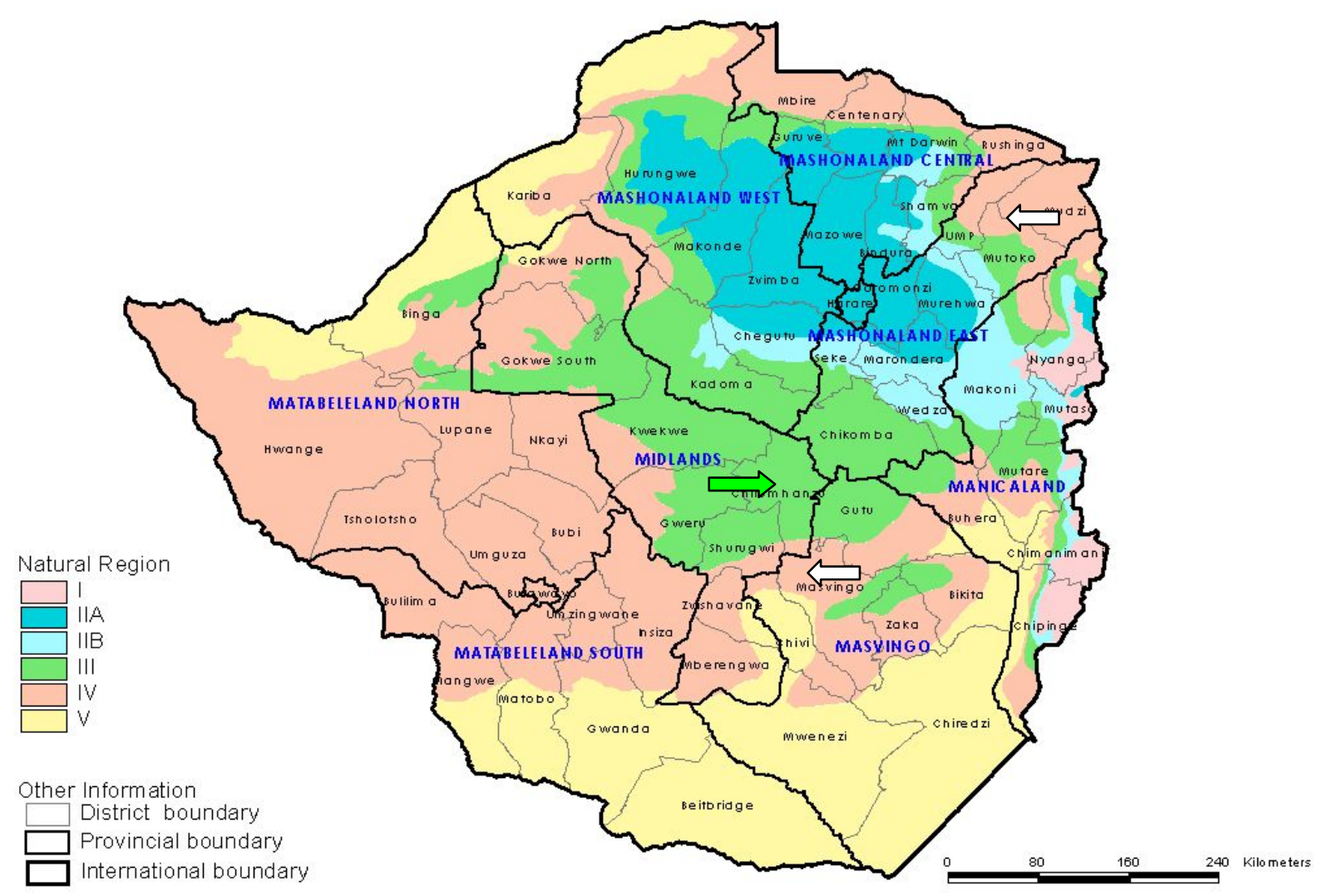

Figure 1. Map showing the survey area: White arrows showing the actual area where survey was conducted while green arrow shows where the pre-testing of the questionnaire was done 


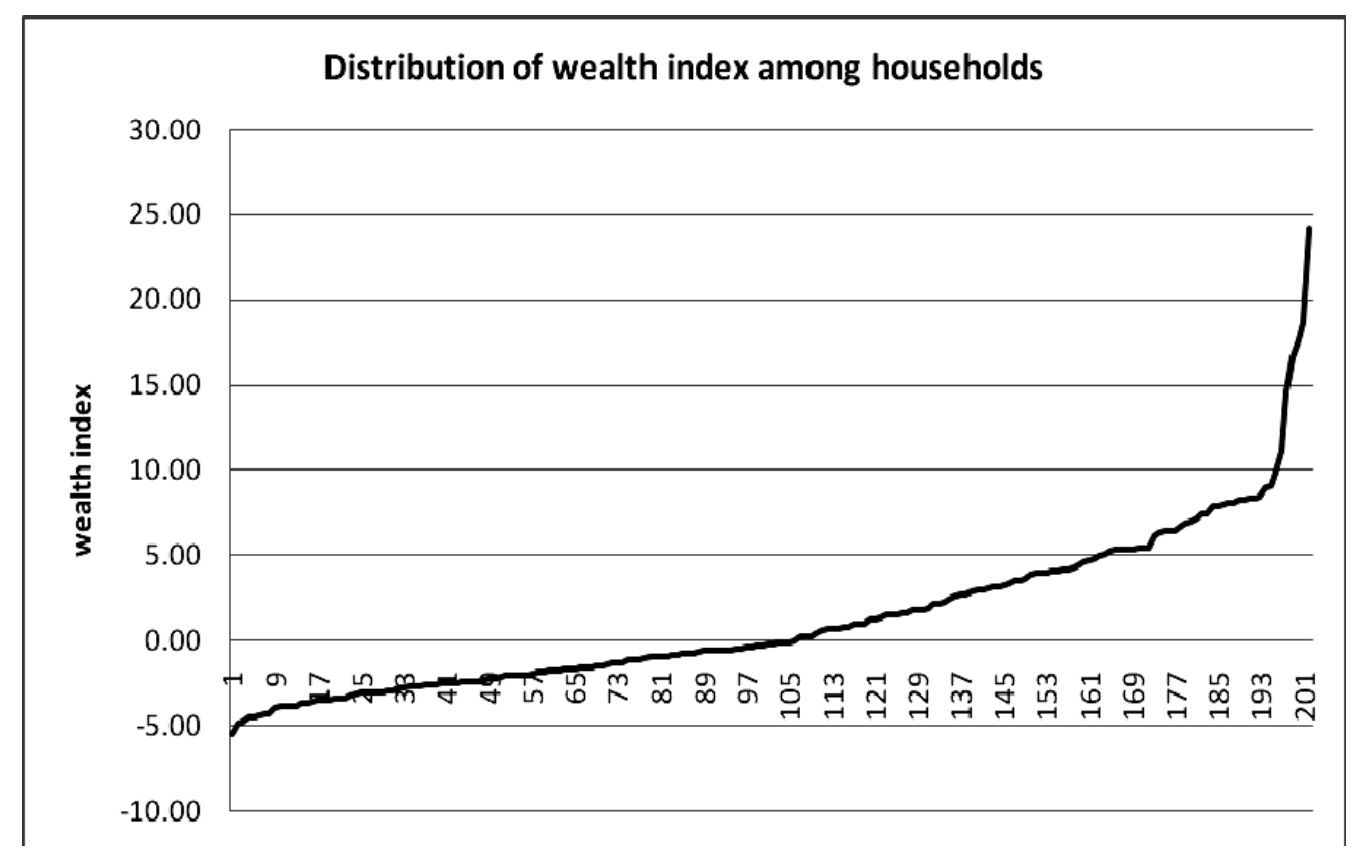

Figure 2. Distribution of wealth index among households

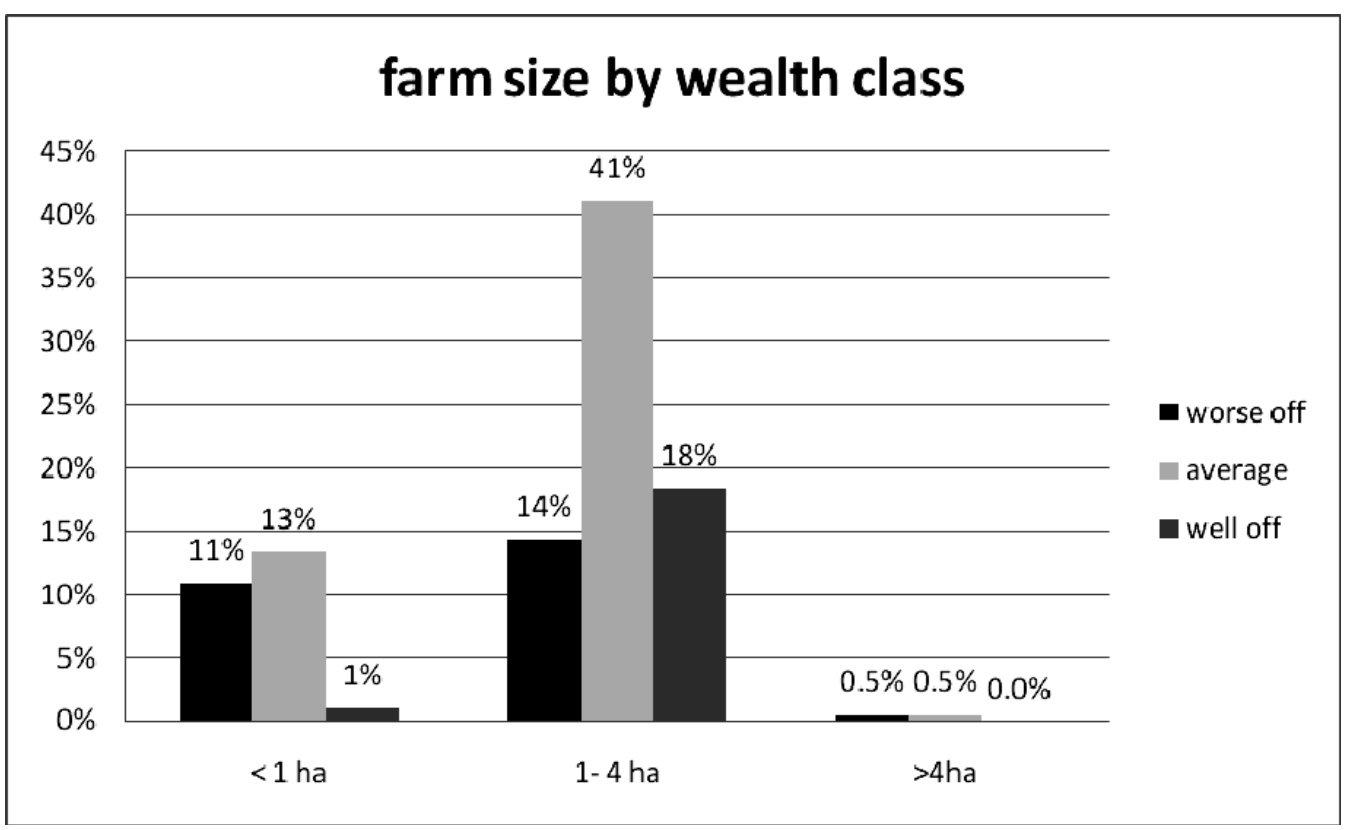

Figure 3. Farm size by wealth class 


\section{Maize production constraints}

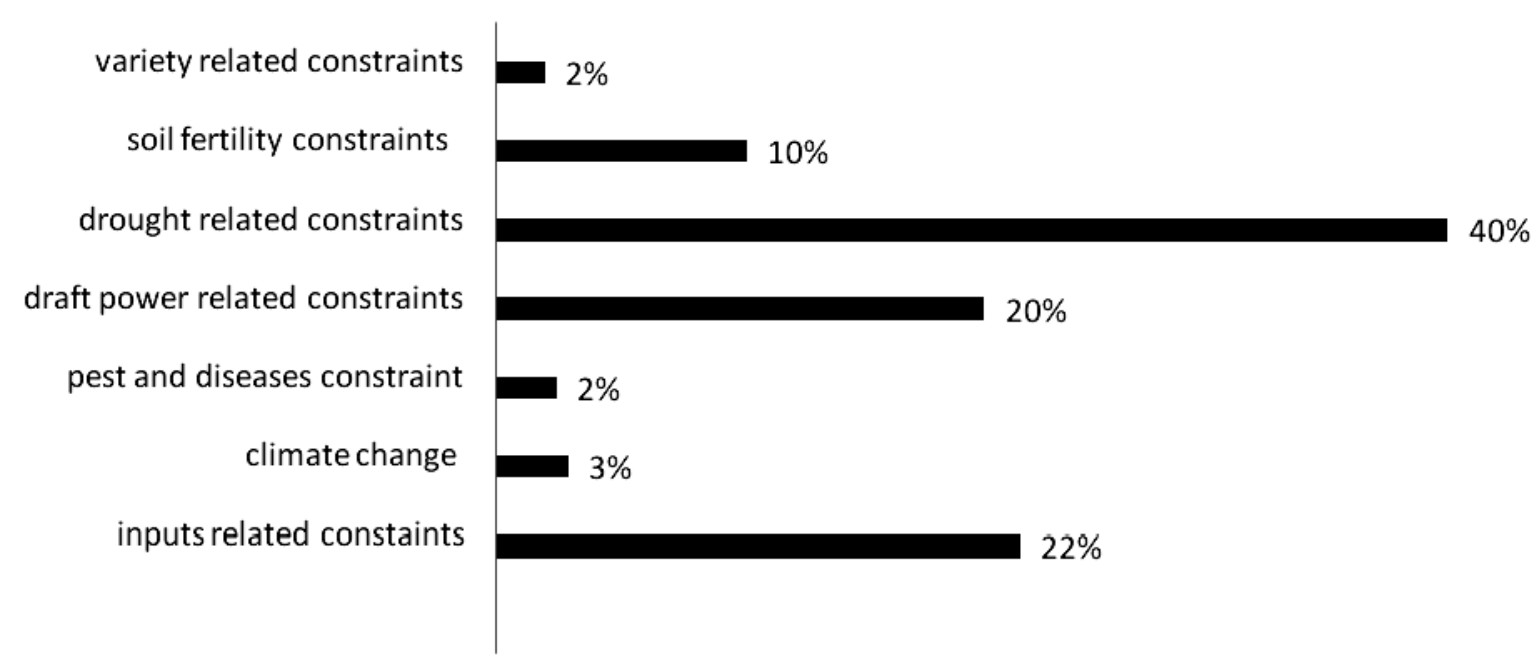

Figure 4. Maize production constraints

\section{Reasons why farmers grow varieties}

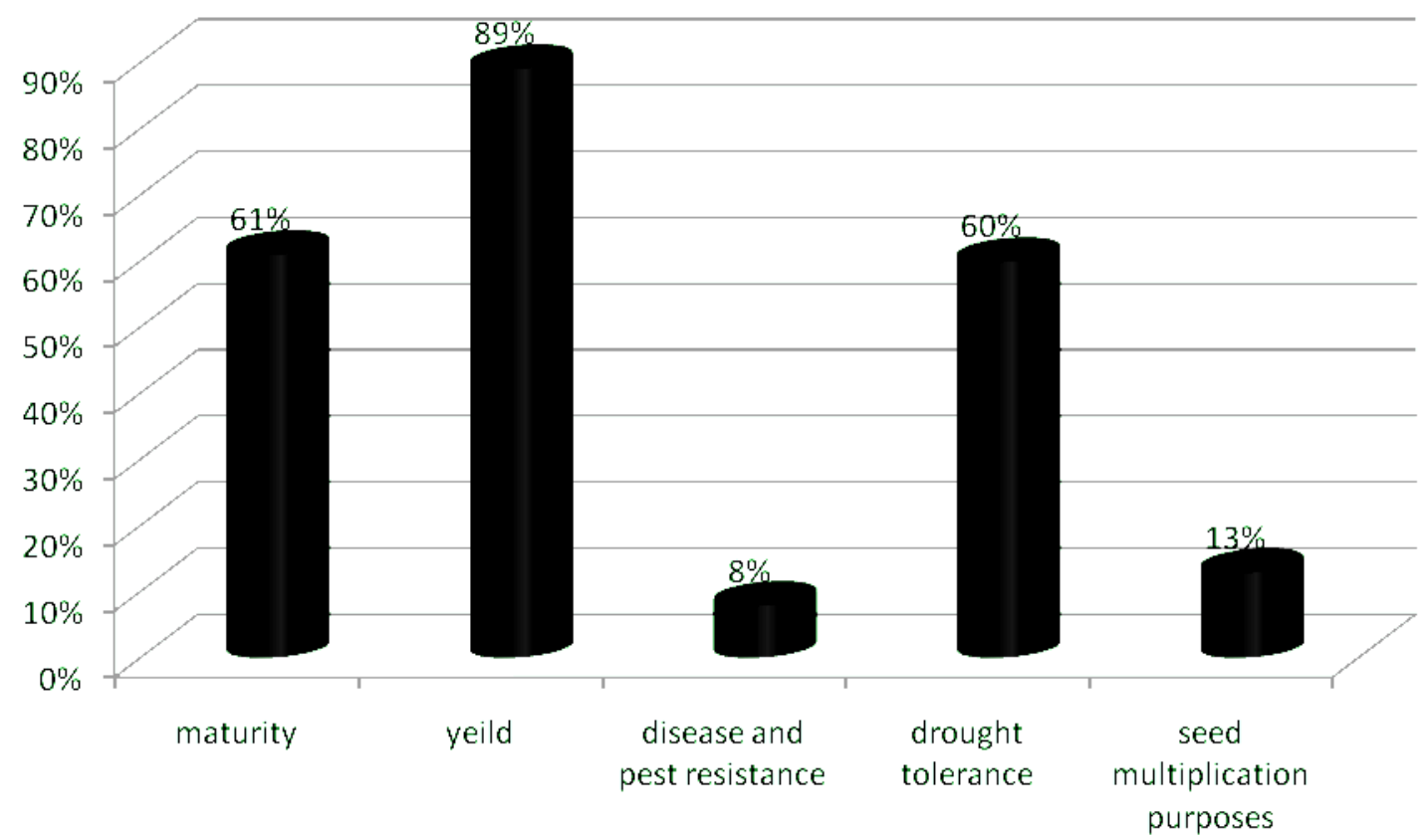

Figure 5. Selection criteria of the maize varieties for growing 


\section{sources of information about drought tolerant varieties}

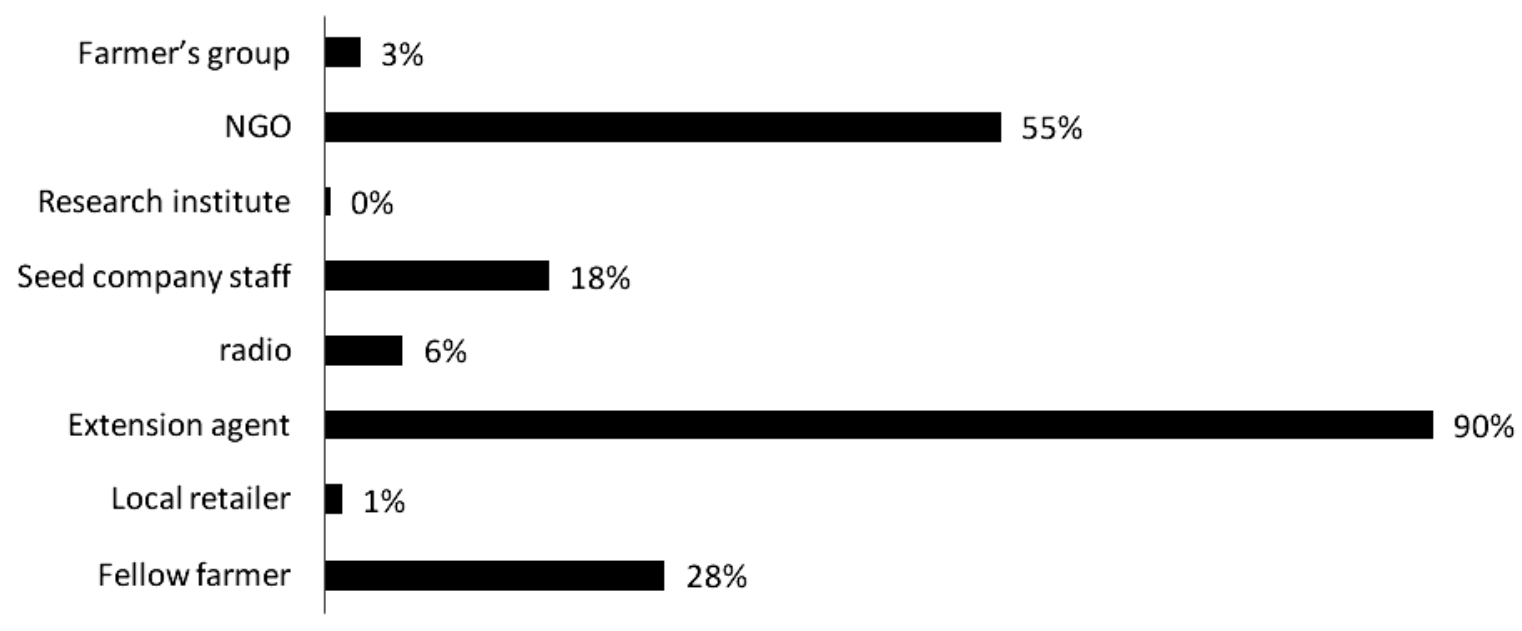

Figure 6. Sources of information on drought tolerant varieties

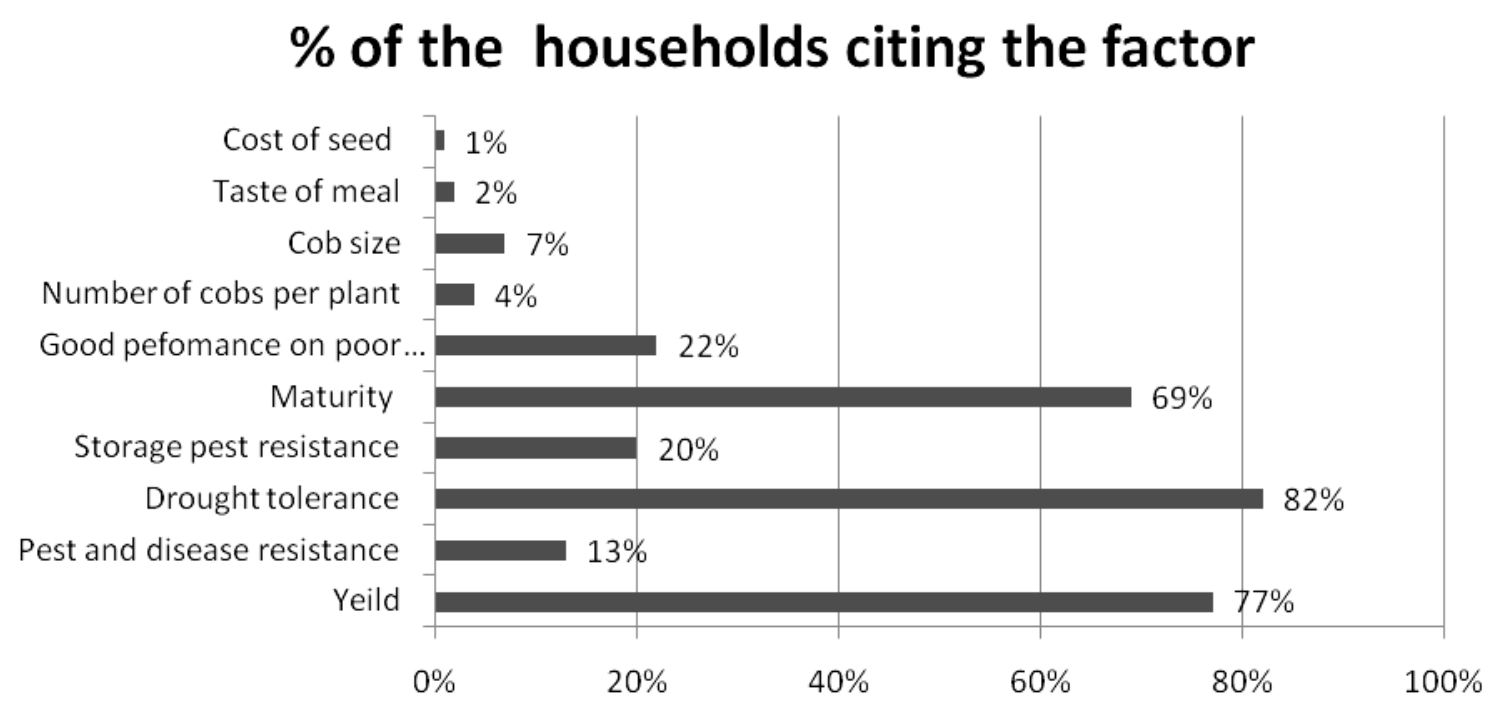

Figure 7. Traits needing improvement in current varieties 


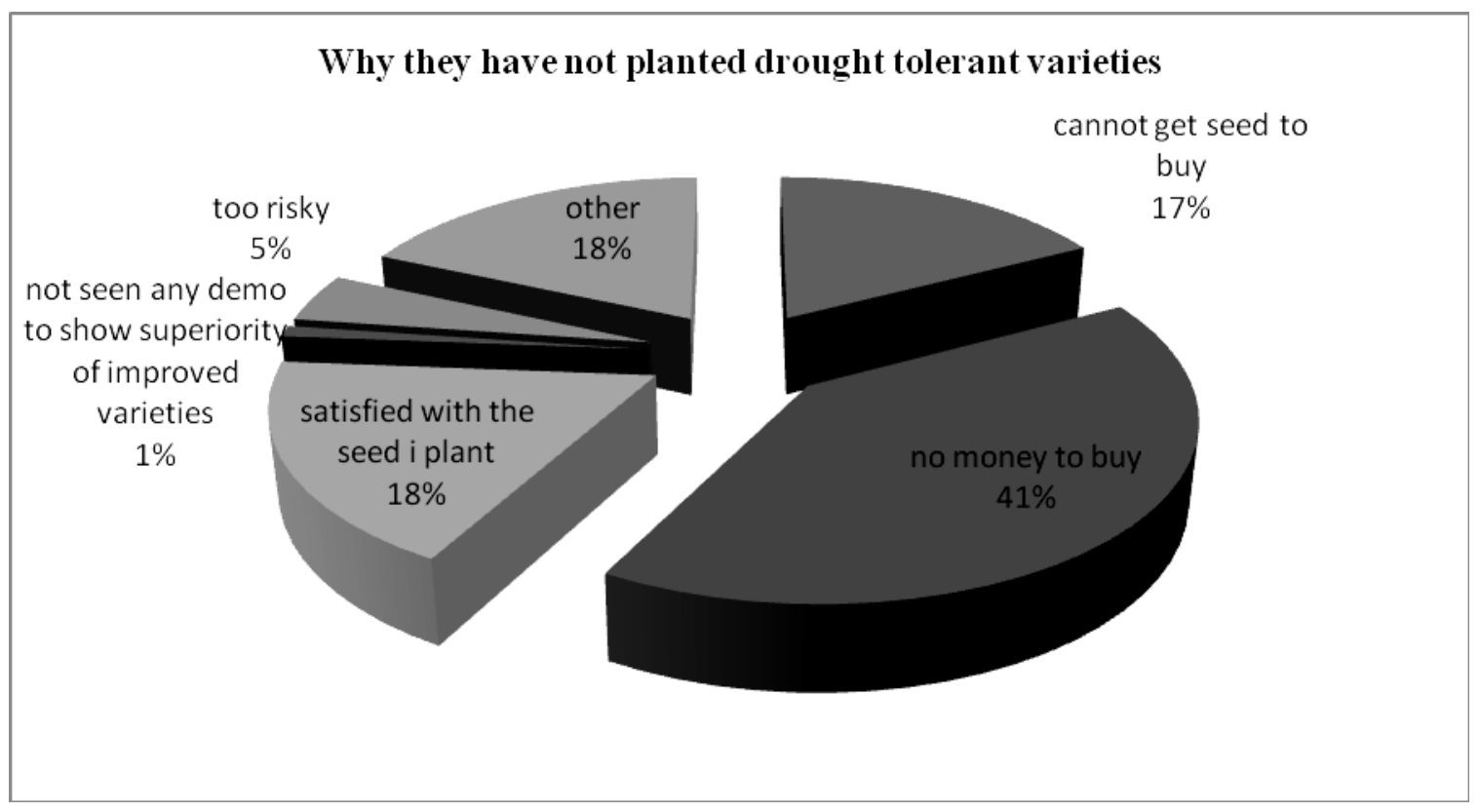

Figure 8. Reasons for not grown drought tolerant varieties 